\title{
Quality of maternal and newborn healthcare services in two public hospitals of Bangladesh: identifying gaps and provisions for improvement
}

Taposh Kumar Biswas ${ }^{1}$, Hasnat Sujon ${ }^{1}$, M. Hafizur Rahman ${ }^{2}$, Henry B. Perry ${ }^{2}$ and Mahbub Elahi Chowdhury ${ }^{1 *}$ (D)

\begin{abstract}
Background: Healthcare service delivery systems need to ensure standard quality of care (QoC) for achieving expected health outcomes. Although Bangladesh has a good healthcare service delivery system, there are major concerns about the quality of maternal and newborn health $(\mathrm{MNH})$ care services, which is imperative for achievements in health. The study aimed to measure the QoC for different MNH services in two selected public health facilities of Bangladesh. This study also documented the specific areas of each care which needs intervention.

Methods: The study was conducted in two district-level public health facilities-a district hospital (DH) and a mother and child welfare centre (MCWC). A total of 228 cases of MNH services were observed by using contextualized checklist 'Standards-based Management and Recognition (S-BMR)' for 8 selected MNH care services. For scoring, performed activities were calculated as percentages of the total recommended activities and categorized as high (> 80\%), moderate (50 to 80\%), and low $(<50 \%)$.

Results: Overall QoC scores were moderate for each DH (54.8\%), and MCWC (56.1\%). In DH, the QoC score was high for blood transfusion (80.3\%); moderate for maternal complications management (77.0\%), caesarean section (CS) (65.6\%), infection prevention (64.3\%), sick newborn care (54.1\%), and normal vaginal delivery (NVD) (52.6\%); and low for antenatal care (ANC) (25.6\%) and postnatal care (PNC) (19.0\%). In MCWC, the QoC scores were high for infection prevention (83.0\%); moderate for CS (76.5\%) and NVD (59.8\%); and low for ANC (36.9\%) and PNC (24.5\%).

Conclusions: In the study facilities, the QoC for MNH services is found to be unsatisfactory, particularly for ANC and PNC. Urgent initiative needs to be taken by introducing contextualized quality monitoring tools at health facilities, along with training of the care providers and introducing a quality monitoring system.
\end{abstract}

Keywords: Bangladesh, Quality of care, Standards-based management and recognition (SBM-R), Maternal and newborn health, Public health facilities

\footnotetext{
* Correspondence: melahi@icddrb.org

'International Centre for Diarrhoeal Disease Research, Bangladesh (icddr,b),

68 Shaheed Tajuddin Ahmed Sarani, Mohakhali, Dhaka 1212, Bangladesh

Full list of author information is available at the end of the article
}

(c) The Author(s). 2019 Open Access This article is distributed under the terms of the Creative Commons Attribution 4.0 International License (http://creativecommons.org/licenses/by/4.0/), which permits unrestricted use, distribution, and reproduction in any medium, provided you give appropriate credit to the original author(s) and the source, provide a link to the Creative Commons license, and indicate if changes were made. The Creative Commons Public Domain Dedication waiver (http://creativecommons.org/publicdomain/zero/1.0/) applies to the data made available in this article, unless otherwise stated. 


\section{Background}

Quality of care (QoC) is a central concern in health systems to improve the health status of population sustainably [1]. The World Health Organization defined quality of maternal and newborn health $(\mathrm{MNH})$ care as "the degree to which maternal and newborn health services (for individuals and population) increase the likelihood of timely, appropriate care for the purpose of achieving desired outcomes that are both consistent with current professional knowledge and take into account the preferences and aspirations of individual women and their family" [2]. There is a complex relationship between quality of healthcare and expected health outcomes. However, the evidence clearly indicates that only increasing the number of facilities will not be sufficient to reduce maternal and neonatal mortality and morbidity unless QoC is maintained [3-7].

In Bangladesh, in each district, there is a district hospital (DH) and a mother and child welfare centre (MCWC). The country has a bifurcated health service delivery system where DHs belong to the Directorate General of Health Services and the MCWCs are under the Directorate General of Family Planning. Though both the directorates are under the Ministry of Health and Family Welfare, the human resources structure and management systems are different in DHs and MCWCs. Nevertheless, most of the DHs have more or less the same human resources, infrastructures, drugs, equipment and service provisions. Likewise, the district level MCWCs are similar in terms of health system readiness and services. Both types of facilities are referral hospitals and usually receive patients from sub-district and below levels of the health system [8]. However, the patients with obstetric and newborn complications are mostly referred to the DHs due to relatively better readiness to manage these complications compared to the MCWCs.

A number of studies have assessed the overall quality of MNH services in Bangladesh. Two studies reported on dissatisfaction of both clients and care providers about the existing QoC $[9,10]$. Another study examined the use of different components of obstetric care services covering the use of partograph, active management of the third stage of labor, management of eclampsia, blood transfusion (BT) service, etc. [11]. However, none of the above studies critically examined the different steps of a particular service provision, which needs to be documented for a clear understanding of the specific gaps and taking necessary actions for improvement of the QoC. One recent study documented the quality of detailed process of normal vaginal delivery (NVD) [12], and another study assessed the quality of antenatal care (ANC) in primary-level health facilities [13]. However, those studies did not assess other MNH services needed during the intranatal and postnatal period.
There are several approaches for measuring the process of different MNH services systematically [14]. The Standards-based Management and Recognition (SBM-R) tool, developed by Jhpiego (Baltimore, MD, USA), has been used in several low-resource African, Asian and American countries to assess the quality of $\mathrm{MNH}$ services [15]. In the current study, we used this tool with an aim to quantify the quality of different $\mathrm{MNH}$ services systematically in two selected public health facilities of Bangladesh. The QoC of MNH services assessed included antenatal, intranatal, and postnatal care as well as management of complications and prevention of infection. This study also attempted to identify the QoC for different components of each $\mathrm{MNH}$ care to develop need-based interventions for ensuring optimum quality of MNH services at health facilities.

\section{Methods}

This was a cross-sectional observational study conducted from February 2014 to May 2015 as part of an operations research to improve delivery and emergency obstetric and newborn care (EmONC) services in public facilities by health systems strengthening in Bangladesh.

\section{Study settings}

The study facilities included a DH and a MCWC in one district with high maternal mortality in Bangladesh. Both the study facilities were secondary-level referral hospitals and designated to provide emergency obstetric and newborn care services. In the $\mathrm{DH}$, there was an obstetrician and three medical doctors for providing $\mathrm{MNH}$ care. One anesthetist was appointed to provide anesthesia services during surgical intervention. Pediatrics services were provided by one specialist provider in both indoor and outdoor departments. Due to having no special care baby unit, sick newborn care was provided in the general paediatrics ward along with all admitted neonates and children. On the other hand, the MCWC had only one trained provider for each of obstetric and anesthesia services. In both the facilities, surgical care was provided by the obstetrician or trained medical doctors but NVDs along with ANC and PNC were mostly conducted by the nurses at $\mathrm{DH}$ and family welfare visitors (FWVs) in MCWC. There was no blood bank in either facility but blood collection and cross-matching services were available in DH. So, blood transfusion services were available when donor was found. The DH usually refer patients to the tertiary level health facilities i.e. medical college hospitals, and specialized hospitals. The MCWC also refer patients to the $\mathrm{DH}$ along with the tertiary hospitals.

\section{Data-collection process}

The SBM-R tools were used to assess the quality of different $\mathrm{MNH}$ care over a period of 30 days. At the 
study facilities, data collection was done during the morning and evening shifts as most of the services were provided during that periods. The SBM-R tools are multifaceted checklists used to measure the quality of MNH care services, which consists of detailed systemic performance standards for assessment of clinical and support systems providing opportunity to identify the gaps $[11,12]$. We contextualized the SBM-R tools according to the service provision and availability of the equipment, supplies and logistics in the study facilities. In each facility, data were collected by a team consisting of one medical doctor and one paramedic. All the members of the datacollection team received training from the study investigators on both technical and ethical aspects of the study.

The study measured the quality of $8 \mathrm{MNH}$ services that included: ANC, postnatal care (PNC), normal vaginal delivery (NVD), caesarean section (CS) delivery, management of maternal complications, sick newborn care, blood transfusion (BT) service, and prevention of infection using contextualized tools (Additional files 1, 2, 3, 4, 5, 6, 7 and 8). To measure the $\mathrm{QoC}$, we observed the performance of service providers to complete the activities recommended for different components of each service [2]. The number of cases observed varied from 5 to 36 for different MNH services in both the study facilities (Table 1).

For each MNH service, all available cases during the 30-day observation period were selected sequentially. The selection of cases depended on the patientflow in those facilities during the observation period. In MCWC, management of maternal complications, sick newborn care, and BT services could not be observed due to unavailability of cases during the study period (Table 1).

\section{Data analysis}

Quality measures were transformed into numerical scores. All activities were equally weighted and given a score of 1 for done, 0 for not done, and null for not applicable. QoC scores were computed as percentages of the total recommended activities that were completed. Scoring was done separately for each component, and an overall QoC score was computed for each $\mathrm{MNH}$ care. Then, averages of the scores of all the observed $\mathrm{MNH}$ services were computed to get an overall score for each facility. For interpretation, we categorized $>80 \%$ QoC scores as high, 50 to $80 \%$ as moderate, and $<50 \%$ as low.

\section{Ethical statement}

Ethical approval of the study was obtained from the Ethics Review Committee of International Centre for Diarrhoeal Disease Research, Bangladesh (icddr,b). Informed written consents were obtained from both service providers and clients of the respective $\mathrm{MNH}$ services before starting observation.

\section{Results}

Overall QoC for $\mathrm{MNH}$ services were moderate in both $\mathrm{DH}$ and MCWC by yielding scores of 55 and $56 \%$ respectively. Though the QoC scores for CS were also moderate in both $\mathrm{DH}(65.6 \%)$ and MCWC (76.5\%), the corresponding scores for $\mathrm{ANC}(\mathrm{DH}=25.6 \%, \mathrm{MCWC}=36.9 \%)$ and PNC $(\mathrm{DH}=19.0 \%, \mathrm{MCWC}=24.5 \%)$ were unacceptably low. In MCWC, the QoC scores for each of the available services were relatively higher than the respective scores in DH. Although the QoC score of BT service in DH was high $(80.3 \%)$, those for management of maternal complications $(77.0 \%)$ and sick newborn $(54.1 \%)$ care were moderate (Fig. 1).

Table 1 Number of cases observed in DH and MCWC by number of components and activities of various MNH service

\begin{tabular}{|c|c|c|c|c|}
\hline \multirow[t]{2}{*}{ Maternal and newborn services } & \multicolumn{2}{|c|}{ Number of cases observed } & \multirow{2}{*}{$\begin{array}{l}\text { Number of } \\
\text { components } \\
\text { per service }\end{array}$} & \multirow{2}{*}{$\begin{array}{l}\text { Number } \\
\text { of } \\
\text { maximum } \\
\text { activities } \\
\text { per service }\end{array}$} \\
\hline & $\mathrm{DH}$ & MCWC & & \\
\hline Antenatal care & 36 & 36 & 8 & 81 \\
\hline Postnatal care & 20 & 18 & 11 & 103 \\
\hline Normal vaginal delivery & 20 & 20 & 16 & 253 \\
\hline Caesarean section & 15 & 14 & 15 & 152 \\
\hline Management of maternal complications & 15 & - & 11 & $54-71^{\mathrm{a}}$ \\
\hline Blood transfusion & 10 & - & 4 & 24 \\
\hline Sick newborn care & 14 & - & 5 & $14-20^{b}$ \\
\hline Prevention of infection & 5 & 5 & 19 & 156 \\
\hline
\end{tabular}

DH District hospital, MCWC Mother and child welfare centre;

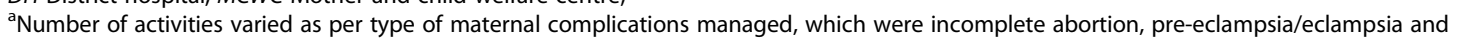
postpartum hemorrhage;

${ }^{\mathrm{b}}$ Number of activities varied as per type of neonatal condition managed, which were preterm/low-birth-weight neonates, neonatal sepsis, and neonatal jaundice 


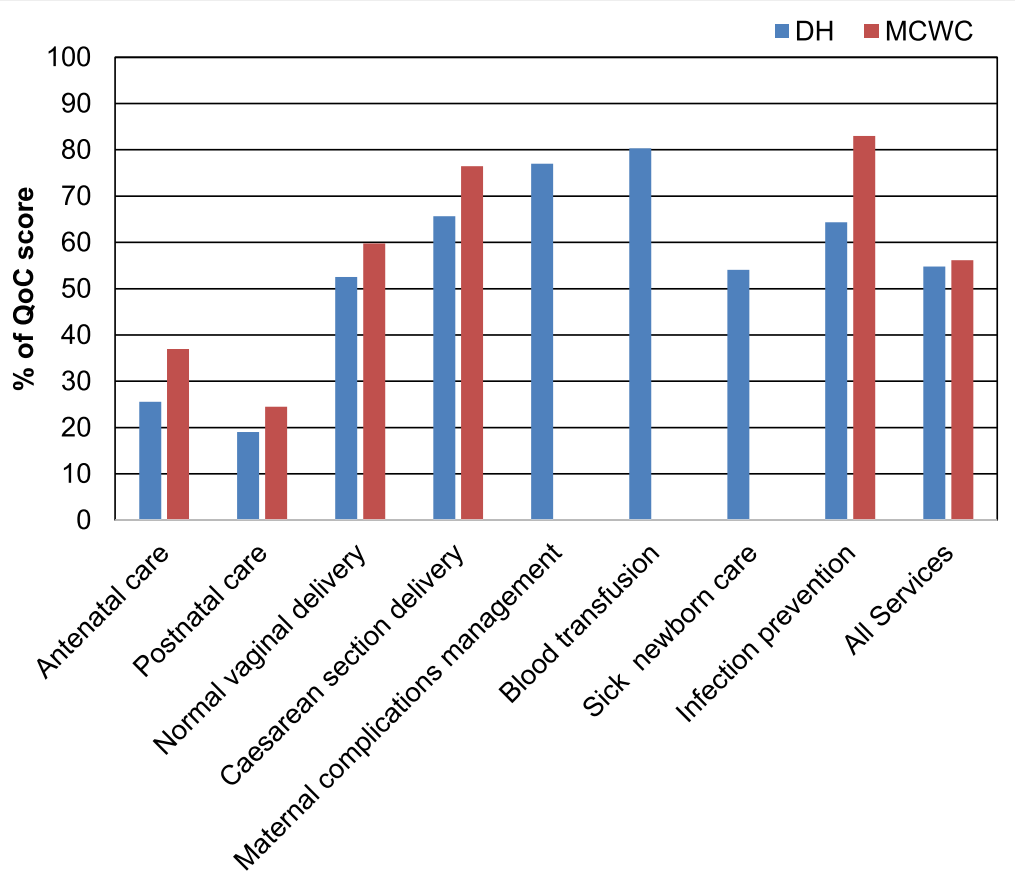

Type of care

Fig. 1 Level of QoC scores for different maternal and newborn care services by type of study facility. QoC = Quality of care, DH=District hospital, MCWC $=$ Mother and child welfare centre

Analysis of each of the components of specific MNH services revealed a wide variation in QoC scores in both the study facilities. In the case of ANC services, out of 8 components/activities, only 2 ('cordial and respectful receiving' and 'obstetrical history-taking') had moderate QoC scores, and the rest 6 components had low QoC scores. For 'birth planning' which includes planning for delivery in advance such as keeping alert skilled birth attendant, arranging emergency transport, saving fund for emergency needs etc., the QoC score was alarmingly low in both the facilities $(\mathrm{DH}=1.5 \%, \mathrm{MCWC}=4.5 \%)$. For PNC service, the QoC scores for 10 out of 11 components were low in both the study facilities. For half of the components of PNC services $(5$ in $\mathrm{DH}$ and 6 in MCWC), the QoC scores were below 20\%. In DH, the service providers failed to obtain any score in 'management of neonates and showing breastfeeding position' and 'advice on baby's danger signs' components of PNC services (Table 2).

The QoC scores for different components of NVD were relatively poorer compared to CS. For NVD in both the study facilities, out of 16 components, only 2 ('assist the woman to have a safe and clean birth' and 'neonatal resuscitation if needed') obtained over $80 \%$ QoC scores. For 3 components of NVD ('rapid initial assessment', 'use of partograph and adjustments to the birth plan', and 'monitoring of newborn in immediate postpartum period'), the QoC scores were $<50 \%$ in both the study facilities. For CS, out of
15 components, 6 ('provide anesthesia', 'opening of abdominal layer', 'opening of the uterus', 'delivery of the baby', 'closure of the uterus', and 'closure of the abdominal wall') achieved high QoC scores (> 80\%) in both the facilities. Of the rest, 3 components ('ensure fitness for surgery through physical and laboratory examinations', 'preparation of operation theater and readiness of providers for surgery' and 'preparation of the patients for surgery') were high in MCWC and moderate in $\mathrm{DH}$. Whereas, 4 components ('informing the clients regarding indication, risks and benefit of CS', 'delivery of the placenta and exploration of the peritoneal cavity' and 'completion of all tasks of post procedure', postoperative monitoring and ensure postnatal care') were moderate in both the facilities. The QoC scores for 'monitoring of newborn in immediate postpartum period' was low in both the study facilities (Table 3).

Regarding management of maternal complications, 5 out of 11 components obtained high QoC scores. The QoC scores were moderate for the 5 other components ('evaluation of patient's response and next step', 'management of incomplete abortion', 'management of severe pre-eclampsia and/or eclampsia', 'general management of PPH', and 'follow-up of the PPH patient') but low in 'cause-specific management of PPH' (Table 4).

The QoC scores for the majority (3 out of 4 ) of the components of sick newborn care were moderate. For 'appropriate diagnosis of a preterm/low-birth-weight neonate', only $31.7 \%$ score was achieved. For half of the 
Table 2 Mean percentages of QoC scores for different components of antenatal care and postnatal care services by type of study facilities

\begin{tabular}{|c|c|c|c|c|}
\hline \multirow[t]{3}{*}{ Components of antenatal and postnatal care services } & \multicolumn{4}{|c|}{$\%$ of QoC score by type of facility } \\
\hline & \multicolumn{2}{|l|}{$\mathrm{DH}$} & \multicolumn{2}{|l|}{ MCWC } \\
\hline & $\begin{array}{l}\text { Number of activities } \\
\text { observed }^{\mathrm{a}}\end{array}$ & $\begin{array}{l}\text { Mean \% of } \\
\text { activities } \\
\text { performed }\end{array}$ & $\begin{array}{l}\text { Number of activities } \\
\text { observed }^{\mathrm{a}}\end{array}$ & $\begin{array}{l}\text { Mean \% of } \\
\text { activities } \\
\text { performed }\end{array}$ \\
\hline \multicolumn{5}{|l|}{ Antenatal care } \\
\hline Rapid initial evaluation & $6-7$ & 15.5 & $6-7$ & 14.8 \\
\hline Cordial and respectful receiving & $4-5$ & 57.1 & $3-5$ & 59.4 \\
\hline Obstetrical history-taking & $5-9$ & 57.1 & $6-9$ & 60.8 \\
\hline General medical history-taking & 8 & 30.2 & 8 & 17.7 \\
\hline Physical and obstetric examination & $10-23$ & 15.3 & $6-23$ & 57 \\
\hline Individualized care, based on findings and protocols & $8-11$ & 32.7 & $7-11$ & 32.1 \\
\hline Birth planning & 13 & 1.5 & 13 & 4.5 \\
\hline Care planning & 5 & 36.1 & 5 & 48.9 \\
\hline \multicolumn{5}{|l|}{ Postnatal care } \\
\hline Rapid initial assessment & $12-13$ & 35.3 & $12-13$ & 29.0 \\
\hline Cordial and respectful receiving & $1-2$ & 40.0 & $1-2$ & 15.6 \\
\hline $\begin{array}{l}\text { Verification of existing clinical records or opening of new one by } \\
\text { appropriate history-taking }\end{array}$ & 4 & 41.3 & 4 & 19.4 \\
\hline Routine physical examination & 14 & 13.6 & $13-14$ & 18.3 \\
\hline Individualized care, based on findings and protocols & $19-25$ & 28.1 & $20-25$ & 37.4 \\
\hline Advice on danger signs of postpartum period & 9 & 6.1 & 9 & 13.6 \\
\hline Referral of mother if needed & 4 & 50.0 & $b$ & - \\
\hline Assessment of the condition of newborn & $1-18$ & 25.9 & $15-18$ & 14.2 \\
\hline Management of neonates and showing breastfeeding position & 3 & 0.0 & 3 & 5.9 \\
\hline Counseling on care of baby & 9 & 7.2 & 9 & 34.0 \\
\hline Advice on baby's danger signs & $6-7$ & 0.0 & $6-7$ & 22.0 \\
\hline
\end{tabular}

QoC Quality of care, DH District hospital, MCWC Mother and child welfare centre

${ }^{a}$ Number of applicable activities varied from case to case

${ }^{\mathrm{b}} \mathrm{No}$ case was available for this component during the study period

components of BT service ('cordial receiving of the patient and response to any query' and 'assessment of the donor for fitness of blood donation'), the QoC scores were either moderate or low (Table 4).

As shown in Table 5, the QoC scores for most of the components of the prevention of infection were relatively high in the MCWC compared to those in $\mathrm{DH}$. Again, QoC scores for prevention of infection in the labor rooms were lower than the corresponding figures in operation theaters in the respective facilities. In DH, the QoC scores were $<50 \%$ for 4 components ('process to clean rooms, wards and clinical areas', 'decontamination of equipment for re-use or storage in labor room', 'use of antiseptics in labor room', and 'collection of soiled linen').

\section{Discussion}

Our study demonstrated that there were major deficiencies in the quality of $\mathrm{MNH}$ services in both the study facilities. Overall, the service providers in these facilities failed to follow about half of the standard activities of $\mathrm{MNH}$ care. In the case of maternal care, the quality was low for ANC and PNC; moderate for NVD, CS and complication management in both the facilities. In the $\mathrm{DH}$, the quality of blood transfusion was high but that of infection prevention and sick newborn care were moderate and low respectively.

The QoC scores for both ANC and PNC were unacceptably low in each DH and MCWC. For both of these services, the $\mathrm{QoC}$ scores for 'rapid initial evaluation', 'cordial and respectful receiving', 'history-taking', 'physical examination' and 'individualized care' were far from satisfactory. Quality was surprisingly low for 'birth planning' component in ANC and for 'neonatal management' component in PNC. Providers in both the facilities rarely advised on 'proper breastfeeding technique' and informed about 'maternal and neonatal danger signs'. A separate study in Bangladesh, using standard operation 
Table 3 Mean percentages of QoC scores for different components of normal vaginal delivery and caesarean section delivery by type of study facility

\begin{tabular}{|c|c|c|c|c|}
\hline \multirow{3}{*}{$\begin{array}{l}\text { Components of normal vaginal and caesarean delivery } \\
\text { care services }\end{array}$} & \multicolumn{4}{|c|}{$\%$ of QoC score by type of facility } \\
\hline & \multicolumn{2}{|l|}{$\mathrm{DH}$} & \multicolumn{2}{|l|}{ MCWC } \\
\hline & $\begin{array}{l}\text { Number of activities } \\
\text { observed }^{\mathrm{a}}\end{array}$ & $\begin{array}{l}\text { Mean } \% \text { of activities } \\
\text { performed }\end{array}$ & $\begin{array}{l}\text { Number of activities } \\
\text { observed }^{\mathrm{a}}\end{array}$ & $\begin{array}{l}\text { Mean \% of } \\
\text { activities } \\
\text { performed }\end{array}$ \\
\hline \multicolumn{5}{|l|}{ Normal vaginal delivery } \\
\hline Rapid initial assessment & 9 & 45.6 & 9 & 46.7 \\
\hline Explanation of services to be provided & 7 & 67.9 & 7 & 73.6 \\
\hline Review and filling-up the clinical history & $16-24$ & 55.3 & $13-24$ & 57.9 \\
\hline Physical examinations between contractions & $12-14$ & 40.1 & $13-14$ & 55.7 \\
\hline Obstetric examination between contractions & 5 & 58.0 & 5 & 72.0 \\
\hline Vaginal examination & $12-13$ & 62.8 & 13 & 74.6 \\
\hline Use of partograph and adjustments to the birth plan & $13-14$ & 9.7 & $13-14$ & 11.0 \\
\hline Preparation for assisting birth & 11 & 42.7 & 11 & 74.5 \\
\hline Assist the woman to have a safe and clean birth & $16-22$ & 80.8 & $16-22$ & 85.8 \\
\hline $\begin{array}{l}\text { Initial assessment of the newborn and providing } \\
\text { immediate newborn care }\end{array}$ & $8-11$ & 78.6 & $8-11$ & 78.4 \\
\hline Active management of the third stage of labor & $16-17$ & 63.0 & $16-17$ & 71.5 \\
\hline Immediate postpartum care & $6-12$ & 68.7 & $6-12$ & 89.7 \\
\hline Disposal of used instruments and medical waste & 10 & 43.5 & 10 & 76.5 \\
\hline $\begin{array}{l}\text { Monitoring of newborn in immediate postpartum } \\
\text { period }\end{array}$ & $10-37$ & 32.8 & $33-37$ & 33.6 \\
\hline $\begin{array}{l}\text { Close monitoring of the woman for at least two hours } \\
\text { after the childbirth }\end{array}$ & $37-39$ & 49.5 & $38-39$ & 54.8 \\
\hline Neonatal resuscitation if needed & $1-13$ & 86.7 & $4-13$ & 100.0 \\
\hline \multicolumn{5}{|l|}{ Caesarean section (CS) delivery } \\
\hline $\begin{array}{l}\text { Informing the clients regarding indication, risks and } \\
\text { benefit of CS }\end{array}$ & $13-14$ & 51.7 & $13-14$ & 65.7 \\
\hline $\begin{array}{l}\text { Ensure fitness for surgery through physical and } \\
\text { laboratory examinations }\end{array}$ & 5 & 52.0 & $4-5$ & 81.4 \\
\hline $\begin{array}{l}\text { Preparation of operation theater and readiness of } \\
\text { providers for surgery }\end{array}$ & 11 & 70.9 & 11 & 83.8 \\
\hline Preparation of the patients for surgery & 7 & 62.9 & 7 & 88.8 \\
\hline Provide anesthesia & $7-8$ & 84.0 & 8 & 95.5 \\
\hline Opening of the abdominal layer & 8 & 84.2 & 8 & 100.0 \\
\hline Opening of the uterus & $7-9$ & 90.0 & $8-9$ & 92.0 \\
\hline Delivery of the baby & 7 & 80.0 & 7 & 89.8 \\
\hline $\begin{array}{l}\text { Delivery of the placenta and exploration of the } \\
\text { peritoneal cavity }\end{array}$ & $4-7$ & 58.1 & $5-7$ & 68.0 \\
\hline Closure of the uterus & $7-9$ & 88.5 & $8-9$ & 96.0 \\
\hline Closure of the abdominal wall & 6 & 98.9 & 6 & 100.0 \\
\hline Completion of all tasks of post procedure & 8 & 55.8 & 8 & 77.7 \\
\hline Postoperative monitoring and ensure postnatal care & $8-16$ & 71.2 & $10-16$ & 79.2 \\
\hline $\begin{array}{l}\text { Monitoring of newborn in immediate postpartum } \\
\text { period }\end{array}$ & 37 & 34.1 & $36-37$ & 33.8 \\
\hline Resuscitation of newborn if needed & $b$ & - & 2 & 50.0 \\
\hline
\end{tabular}

QoC Quality of care, DH District hospital, MCWC Mother and child welfare centre ${ }^{a}$ Number of applicable activities varied from case to case

${ }^{\mathrm{b}}$ No case was available for this component during the study period 
Table 4 Mean percentages of QoC scores for different components of maternal and newborn complications management and blood transfusion services in $\mathrm{DH}$

\begin{tabular}{|c|c|c|}
\hline \multirow{2}{*}{$\begin{array}{l}\text { Components of maternal and newborn complications } \\
\text { management and blood transfusion services }\end{array}$} & \multicolumn{2}{|l|}{$\%$ of QoC score } \\
\hline & $\begin{array}{l}\text { Number of activities } \\
\text { observed }^{\mathrm{a}}\end{array}$ & $\begin{array}{l}\text { Mean } \% \text { of activities } \\
\text { performed }\end{array}$ \\
\hline \multicolumn{3}{|l|}{ Management of maternal complications } \\
\hline Availability of drugs, equipment, and supplies & 4 & 89.5 \\
\hline Management of hypovolemic shock & $4-14$ & 81.9 \\
\hline Evaluation of patient's response and next step & $6-11$ & 67.7 \\
\hline Diagnosis of incomplete abortion & $6-7$ & 90.5 \\
\hline Management of incomplete abortion & $5-8$ & 68.8 \\
\hline Diagnosis of pre-eclampsia/eclampsia & $3-4$ & 91.7 \\
\hline Management of severe pre-eclampsia and/or eclampsia & $11-16$ & 76.0 \\
\hline Diagnosis of PPH & 1 & 100.0 \\
\hline General management of PPH & $14-17$ & 62.3 \\
\hline Cause-specific management of PPH & $1-12$ & 49.0 \\
\hline Follow-up of the PPH patient & $6-8$ & 59.9 \\
\hline \multicolumn{3}{|l|}{ Sick newborn care } \\
\hline Receiving patient, history-taking, and explanation of the condition & 5 & 70.0 \\
\hline $\begin{array}{l}\text { Appropriate diagnosis and management of a preterm/low-birth- } \\
\text { weight neonate }\end{array}$ & $12-15$ & 31.7 \\
\hline Diagnosis of neonatal sepsis and appropriate referral if required & $8-9$ & 53.0 \\
\hline Diagnosis of neonatal jaundice and appropriate referral if required & $6-9$ & 51.9 \\
\hline \multicolumn{3}{|l|}{ Blood transfusion services } \\
\hline Cordial receiving of the patient and response to any query & 4 & 55.0 \\
\hline Assessment of the donor for fitness of blood donation & 4 & 75.0 \\
\hline Blood-collection procedure & 6 & 91.7 \\
\hline Appropriate blood transfusion procedure & $9-10$ & 86.8 \\
\hline
\end{tabular}

QoC Quality of care, DH District hospital, MCWC Mother and child welfare centre, PPH Postpartum hemorrhage

${ }^{\mathrm{a}}$ Number of applicable activities varied from case to case

procedures of the Directorate General of Health Services [13], documented relatively high quality of ANC service compared to our study. However, that study was conducted in primary health facilities, and the variations in findings might be due to difference in the context.

Lack of refresher training and inadequate human resources might have contributed to the poor quality of care in secondary facilities [10]. Since the quality of ANC influences pregnancy outcomes [16] and a high burden of maternal and neonatal mortality exists during the postnatal period [17], standard QoC needs to be maintained. In addition to increasing human resource, special orientation programmes and refresher training for the service providers with emphasis on the low scoring areas might be useful for improving the quality of $\mathrm{ANC}$ and PNC.

Although the service providers in both the facilities of our study could perform more than half and threefourths of the total standard activities while providing NVD and CS delivery services respectively, there is still considerable room for further improvement of the quality of these services. Providers in these facilities performed poorly in providing newborn care immediately after NVD and CS delivery. For NVD, the quality fell due to poor performance in 'rapid initial assessment' and 'physical examination'. More than one-third of the activities in 'active management of the third stage of labor' that needed to be addressed properly for prevention of PPH, was not performed [18]. The QoC scores for using partograph in both the facilities were extremely poor. Similar findings were also documented in a previous study [12]. The care providers might not be in a position to use the labor-monitoring tool due to lack of training and high patient-load [19]. Our study found that clients were inadequately counseled on indications, risks, and benefits of CS. Another study revealed that there was skepticism among clients about the service providers' justification of CS in Bangladesh [20]. To improve the situation, adequate training should be provided to human resources with emphasis on clinical assessment 
Table 5 Mean percentages of QoC scores for different components of infection prevention services by type of facility

\begin{tabular}{|c|c|c|c|c|}
\hline \multirow[t]{3}{*}{ Components of infection prevention } & \multicolumn{4}{|c|}{$\%$ of QoC score by type of facility } \\
\hline & \multicolumn{2}{|l|}{$\overline{\mathrm{DH}}$} & \multicolumn{2}{|l|}{ MCWC } \\
\hline & $\begin{array}{l}\text { Number of activities } \\
\text { observed }^{\mathrm{a}}\end{array}$ & $\begin{array}{l}\text { Mean } \% \text { of activities } \\
\text { performed }\end{array}$ & $\begin{array}{l}\text { Number of activities } \\
\text { observed }^{\text {a }}\end{array}$ & $\begin{array}{l}\text { Mean } \% \text { of activities } \\
\text { performed }\end{array}$ \\
\hline $\begin{array}{l}\text { Cleanliness of facility and availability of clean running } \\
\text { water }\end{array}$ & $12-14$ & 52.6 & $13-14$ & 91.2 \\
\hline Process to clean rooms, wards, and clinical areas & 23 & 41.7 & 23 & 70.4 \\
\hline \multicolumn{5}{|l|}{ Decontamination of equipment for re-use or storage } \\
\hline Labor room & 5 & 48.0 & 5 & 88.0 \\
\hline Operation theater & 5 & 80.0 & 5 & 100.0 \\
\hline \multicolumn{5}{|l|}{ Use of antiseptics } \\
\hline Labor room & 7 & 40.0 & 7 & 62.9 \\
\hline Operation theater & 7 & 60.0 & 7 & 82.9 \\
\hline \multicolumn{5}{|l|}{ Instrument cleaning area } \\
\hline Labor room & 9 & 77.8 & 9 & 80.0 \\
\hline Operation theater & 9 & 86.7 & 9 & 91.1 \\
\hline \multicolumn{5}{|l|}{ Decontamination of instruments } \\
\hline Labor room & 5 & 56.0 & 5 & 84.0 \\
\hline Operation theater & 5 & 72.0 & 5 & 80.0 \\
\hline \multicolumn{5}{|l|}{ Process of cleaning instruments } \\
\hline Labor room & 7 & 77.1 & 7 & 94.3 \\
\hline Operation theater & 7 & 80.0 & 7 & 94.3 \\
\hline Area for wrapping and packing instruments & 3 & 60.0 & 3 & 66.7 \\
\hline $\begin{array}{l}\text { Process of packaging of instruments and other items for } \\
\text { sterilization }\end{array}$ & 4 & 80.0 & 4 & 95.0 \\
\hline Sterilization process & $17-18$ & 71.8 & $16-18$ & 91.6 \\
\hline High-level disinfection process & 4 & 90.0 & 4 & 100.0 \\
\hline $\begin{array}{l}\text { Availability of antiseptics, disinfectants, and other } \\
\text { supplies }\end{array}$ & 14 & 61.4 & 14 & 78.6 \\
\hline Collection of soiled linen & 3 & 26.7 & 3 & 40.0 \\
\hline $\begin{array}{l}\text { Following of general biosafety and infection prevention } \\
\text { practices in the laboratory }\end{array}$ & 7 & 97.1 & b & - \\
\hline
\end{tabular}

QoC Quality of care, $D H$ District hospital, MCWC Mother and child welfare centre ${ }^{a}$ Number of applicable activities varied from case to case

${ }^{\mathrm{b}}$ As no laboratory service was available in MCWC

and monitoring. Advocacy program needs to be endorsed to motivate the service providers for using labour monitoring tool like partograph in order to observe progress in labour and foetal condition and make decision for appropriate intervention.

Standards of quality must be maintained while managing maternal and newborn complications to reduce the risk of serious complications and avert death. We found that the service providers completed most of the activities in general management of maternal complications and diagnosis of specific causes. However, the quality of management of specific conditions, such as pre-eclampsia/eclampsia and incomplete abortion was deficient. Poor quality of PPH management is a serious concern as it is the single-most important cause of maternal mortality [21]. Most prevalent causes of neonatal deaths included prematurity, birth complications (birth asphyxia and trauma) and sepsis [22]. Our findings on poor QoC in identifying specific newborn complications and lacking in providing appropriate care are similar to those from another study in Bangladesh [23]. We also documented substantially low performance in appropriate diagnosis of preterm and low-birth-weight neonates. Quality of diagnosis and referral for neonatal sepsis and jaundice were low mainly due to care providers' poor practice to recognize the signs/symptoms of these complications. The current low qualities of sick newborn care service at these district-level facilities in Bangladesh 
need to be improved through special training program of the service providers. While assessing BT service, we found that standards in receiving the clients and assessing the blood donor for fitness were not maintained properly and that may enhance the risk of getting infected by intravenously transmitted diseases among the patients. Intermittent advocacy program and refresher training of the service providers may help overcome these inadequacies.

Although overall QoC scores for prevention of infection was better in the MCWC, component-wise analysis revealed that the quality of the 'use of antiseptics in labor room'; 'availability of the antiseptics, disinfectants, and other supplies'; and 'collection of soiled linen' was inadequate in both the study facilities. These shortcomings, along with the low score for sterilization processes in $\mathrm{DH}$, increase the risk of hospital-acquired infection of mothers and newborns. The main cause of hospital-acquired infection is the substandard practice for prevention of infection and simple strategies, such as hand washing which can reduce this burden significantly [24]. As prevention of infection is a broad issue; the support staff of the hospitals, along with the care providers, should be appropriately trained to ensure proper sterility. Behavior change education, monitoring and supportive supervision of the staff may improve the situation [25].

One limitation of our study is that we did not correlate the QoC with availability of human resources, functioning equipment, logistics and supplies. However, the poor quality of primary $\mathrm{MNH}$ care in the study facilities is likely to be due to inadequate human resource and high patient load that had been documented in our another paper [26] developed from the same study. This also has been confirmed by the service providers while sharing the study findings with them. In addition to training of the existing manpower, they suggested to ensure availability of adequate human resources to practice the QoC protocols for various $\mathrm{MNH}$ care services. Another limitation of the study is not considering the delay in providing services at health facilities. Further qualitative studies are needed to explore the impact of delay in providing services on quality of MNH services. In this study, we observed the patients for QoC only during the morning and shifts. Not observing services at the night shift does not likely to affect the findings as the services are scanty is public facilities during that period. Only one month observation time period was another limitation in capturing adequate number of infrequent services (such as complication management, infection prevention and BT). This short observation period also did not allow us to mitigate the seasonal dips. Above all, we did not apply weights for different activities of various MNH services, as there is no standard available in the literature.
Substandard QoC in the public health sector in Bangladesh might have contributed to the recent lack of progress in health indicators [4]. The Government has developed national healthcare standards on QoC [27] but these are yet to be implemented and lack many important technical details. There is a need to develop a contextualized facility-specific quality monitoring tool of $\mathrm{MNH}$ service by reviewing $S B M-R$ and other existing methods through expert consultation. Self-implementation of the newly-developed quality assessment tool can be a way of improving the QoC, and, for that purpose, training activities and motivation programs for service providers should be undertaken.

\section{Conclusions}

In Bangladesh, QoC for $\mathrm{MNH}$ services in the $\mathrm{DH}$ and MCWC is much below the acceptable level. The QoC is alarmingly low for the ANC and PNC services. To improve the situation, there is an urgent call for developing facility-specific contextualized tools and implement those through appropriate training and supportive supervision for maintaining minimum required quality of $\mathrm{MNH}$ care. An external quality-monitoring team should be vigilant to ensure accountability of the health facilities in providing quality services.

\section{Supplementary information}

Supplementary information accompanies this paper at https://doi.org/10. 1186/s12884-019-2656-1.

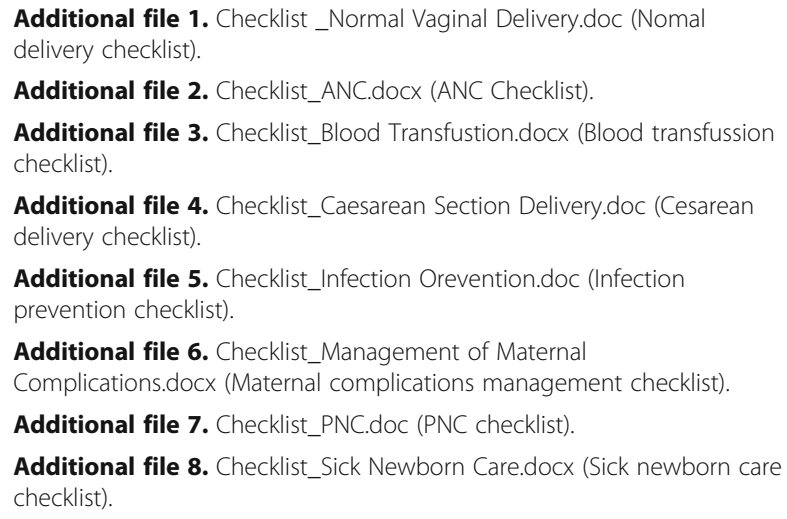

Additional file 4. Checklist_Caesarean Section Delivery.doc (Cesarean delivery checklist).

Additional file 5. Checklist_Infection Orevention.doc (Infection prevention checklist).

Additional file 6. Checklist_Management of Maternal Complications.docx (Maternal complications management checklist).

Additional file 7. Checklist_PNC.doc (PNC checklist).

Additional file 8. Checklist_Sick Newborn Care.docx (Sick newborn care checklist).

\section{Abbreviations \\ ANC: Antenatal care; BT: Blood transfusion; CS: Caesarean section; DH: District hospital; icddr,b: International centre for diarrhoeal disease research, Bangladesh; MCWC: Mother and child welfare centre; MNH: Maternal and newborn healthcare; NVD: Normal vaginal delivery; PNC: Postnatal care; QoC: Quality of care; SBM-R: Standards-based management and recognition}

\section{Acknowledgements}

We are grateful to the Ministry of Health and Family Welfare of the Government of Bangladesh for allowing us to conduct the study in their health facilities. Also acknowledge the support of "MaMoni" project of SavetheChildren for their co-operation during implementation of the study. 


\section{Authors' contributions}

TKB generated the idea of creating score on quality of MNH care provided at the health facilities and drafted the manuscript. MEC had conceptualized the main study, contributed in writing and critically reviewing the manuscript. HS participated in data analysis, interpretation of the results and writing of the manuscript. MHR and HBP critically reviewed the manuscript and gave substantial inputs in writing. All the authors have read and approved the manuscript in its current state.

\section{Authors' information}

TKB is a researcher and affiliated with International Centre for Diarrhoeal Diseases Research, Bangladesh (icddr,b), Dhaka, Bangladesh. HS is also a researcher at icddr,b. MHR and HBP are faculty members in the Health Systems Program of the Department of International Health of the Johns Hopkins Bloomberg School of Public Health, Baltimore, MD, USA. The corresponding author MEC is a scientist and affiliated with icddr,b.

\section{Funding}

This study was fully funded by the United States Agency for International Development (USAID) under the TRAction project to icddr,b through University Research Co., LLC (URC), Sub agreement No. FY11-G04-699 under Cooperative Agreement No. GHS-A-00-09-00015-00. The funder had no role in the design of the study, collection, analysis, interpretation of data and, in writing the manuscript.

\section{Availability of data and materials}

The detail dataset is available with MEC, the Principal Investigator of the main study. A copy of the original data is also stored in the data archive of icddr,b. These data are not publicly available. However, non-identifiable data can be accessible upon request subject to approval of the Research Administration Department of icddr,b.

\section{Ethics approval and consent to participate}

Ethical approval to conduct the study was obtained from the Ethics Review Committee of International Centre for Diarrhoeal Disease Research, Bangladesh (icddr,b). Informed written consents were obtained from both service providers and clients of the respective MNH services before starting observation.

\section{Consent for publication}

"Not applicable" as no personal information is provided in this manuscript.

\section{Competing interests}

We declare that none of the authors have any competing interest.

\section{Author details}

${ }^{1}$ International Centre for Diarrhoeal Disease Research, Bangladesh (icddr,b), 68 Shaheed Tajuddin Ahmed Sarani, Mohakhali, Dhaka 1212, Bangladesh. 2Johns Hopkins University Bloomberg School of Public Health, Baltimore, MD, USA.

Received: 22 October 2018 Accepted: 2 December 2019

Published online: 10 December 2019

\section{References}

1. World Health Organization, Organization for Economic Co-operation and Development, and The World Bank. Delivering quality health services: a global imperative for universal health coverage. Geneva, 2018. https:// extranet.who.int/sph/docs/file/1654.

2. World Health Organization. Standards for improving quality of maternal and newborn care in health facilities. 2016. http://apps.who.int/iris/bitstream/1 0665/249155/1/9789241511216-eng.pdf?ua=1.

3. World Health Organization. WHO multicountry survey on maternal and newborn health 2010-2012. http://www.who.int/reproductivehealth/topics/ maternal_perinatal/nearmiss/en.

4. National Institute of Population Research and Training (NIPORT), International Centre for Diarrhoeal Disease Research Bangladesh, Measure Evaluation. Bangladesh Maternal Mortality and Health Care Survey 2016: Preliminary Report. https://www.measureevaluation.org/resources/ publications/tr-17-218/at_download/document.
5. Souza JP, Gülmezoglu AM, Vogel J, Carroli G, Lumbiganon P, Qureshi Z, et al. Moving beyond essential interventions for reduction of maternal mortality (the WHO Multicountry Survey on Maternal and Newborn Health): a cross-sectional study. Lancet. 2013 18;381(9879):1747-1755.

6. Okeke EN, Chari AV. Can institutional deliveries reduce newborn mortality? Evidence from Rwanda. Santa Monica: RAND Corporation; 2015. http:// www.rand.org/pubs/working_papers/WR1072.html. .

7. Ronsmans C, Chowdhury ME, Koblinsky M, Ahmed A. Care seeking at time of childbirth, and maternal and perinatal mortality in Matlab, Bangladesh Bull WHO April 2010;88(4):241-320.

8. Chowdhury ME, Roy L, Biswas TK, Rahman M, Akhter S, Sabir AA. A needs assessment study for emergency obstetric and newborn care (EmONC) services in 24 districts of Bangladesh. Int Cent Diarrhoeal Disease Research, April 2014; 348p.

9. Chowdhury S, Hossain SA, Halim A. Assessment of quality of care in maternal and newborn health services available in public health care facilities in Bangladesh. Bangladesh Med Res Counc Bull. 2009;35:53-6.

10. Islam F, Rahman A, Halim A, Eriksson C, Rahman F, Dalal K. Perceptions of health care providers and patients on quality of care in maternal and neonatal health in fourteen Bangladesh government healthcare facilities: a mixed-method study. BMC Health Serv Res. 2015;15:237.

11. Anwar I, Kalim N, Koblinsky M. Quality of obstetric care in public-sector facilities and constraints to implementing emergency obstetric care services: evidence from high and low performing districts of Bangladesh. J Health Popul Nutr. 2009;27:139-55.

12. Nababan HY, Islam R, Mostari S, et al. Improving quality of care for maternal and newborn health: apre-post evaluation of the Safe Childbirth Checklist at a hospital in Bangladesh. BMC Pregnancy Childbirth. 4 December 2017;17(1):402.

13. Amed MS, Karim MR, Haque MM, Chowdhury S. Quality of antenatal Care in Primary Health Care Centers of Bangladesh. J Fam Reprod Health. 2014;8:4.

14. Board on Global Health, Institute of Medicine, The National Academies of Sciences, Engineering, and Medicine. Improving Quality of Care in Low- and Middle-Income Countries: Workshop Summary. Washington (DC): National Academies Press (US); 2015. 3, Six Widely Used Methods to Improve Quality. https://www.ncbi.nlm.nih.gov/ books/NBK333244. .

15. Necochea E, Tripathi $V$, Kim $Y$, et al. Implementation of the standards-based management and recognition approach to quality improvement in maternal, newborn, and child health programs in low-resource countries. Int J Gynaecol Obstet Jun 2015;130(Suppl 2):S17-S24.

16. Khatun S, Rahman M. Quality of antenatal care and its dose-response relationship with birth weight in a maternal and child health training institute in Bangladesh. J Biosoc Sci. 2008;40(3):321-37.

17. World Health Organization. WHO recommendations on postnatal care of the mother and newborn 2013 [WHO website]. 2013 http://apps.who.int/ iris/bitstream/10665/97603/1/9789241506649_eng.pdf?ua=1. .

18. Leduc $D$, Senikas $V$, Lalonde $A B$, et al. Active management of the third stage of labor: prevention and treatment of postpartum hemorrhage. J Obstet Gynaecol Can Oct.2009;31(10):980-993.

19. Ollerhead E, Osrin D. Barriers to and incentives for achieving partograph use in obstetric practice in low- and middle-income countries: a systematic review. BMC Pregnancy and Childbirth. 2014;14:281.

20. Parkhurst JO, Rahman SA. Life saving or money wasting? Perceptions of caesarean sections among users of services in rural Bangladesh. Health Policy March 2007:80(3):392-401.

21. Khan KS, Wojdyla D, Say L, Gülmezoglu AM, Van Look PF. WHO analysis of causes of maternal death: a systematic review. Lancet. 2006;367:1066-74.

22. UNICEF. Maternal and Newborn Health Disparities in Bangladesh. Key facts, 2019.https://data.unicef.org/wp-content/uploads/.../Bangladesh/country\%2 Oprofile_BGD.pd.

23. Hoque DME, Rahman M, Billah SM, Savic M, Karim AQMR, Chowdhury EK et. el. An assessment of the quality of care for children in eighteen randomly selected district and sub-district hospitals in Bangladesh. BMC Pediatrics, 2012;12 (197). https://bmcpediatr.biomedcentral.com/articles/https://doi.org/ 10.1186/1471-2431-12-197.

24. Fernando SA, Gray TJ, Gottlieb T. Healthcare-acquired infections: prevention strategies. Intern Med J. 2017;47:1341-51.

25. Tietjen L, Bossemeyer D, McIntosh N. Infection Prevention Guidelines for Healthcare Facilities with Limited Resources. JHPIEGO Corporation, 2003. https://pdf.usaid.gov/pdf_docs/Pnact433.pdf. .

26. Biswas TK, Begum AA, Akhter S, Rahman MH, Perry HB, Jones H, Chowdhury ME. A newly developed tool for measuring the availability of human 
resources for emergency obstetric and newborn care services: prospective analytic study in two district-level public facilities in Bangladesh. BMC Health Serv Res. 2018;18:688.

27. Quality Improvement Secretariat, Ministry of Health \& Family Welfare, Bangladesh. National health care standards. 2015. http://www.qis.gov.bd/ admn/joint/2017_02_26_1488073894_902rds_pdf.

\section{Publisher's Note}

Springer Nature remains neutral with regard to jurisdictional claims in published maps and institutional affiliations.

Ready to submit your research? Choose BMC and benefit from:

- fast, convenient online submission

- thorough peer review by experienced researchers in your field

- rapid publication on acceptance

- support for research data, including large and complex data types

- gold Open Access which fosters wider collaboration and increased citations

- maximum visibility for your research: over $100 \mathrm{M}$ website views per year

At BMC, research is always in progress.

Learn more biomedcentral.com/submissions 